\title{
Ipilimumab, not just another anti-cancer therapy: hypophysitis as side effect illustrated by four case-reports
}

\author{
Joke Marlier • Veronique Cocquyt • \\ Lieve Brochez $\cdot$ Simon Van Belle $\cdot$ Vibeke Kruse
}

Received: 16 September 2013/ Accepted: 31 January 2014/Published online: 21 February 2014

(C) Springer Science+Business Media New York 2014

\begin{abstract}
Ipilimumab is a monoclonal antibody that blocks cytotoxic T-lymphocyte antigen4 (CTLA-4), an inhibitory molecule typically expressed on $\mathrm{T}$ cells. Blockade of CTLA-4 induces an overall activation of $\mathrm{T}$ cells, including an immune-mediated anti-tumour response. Unfortunately, this broad $\mathrm{T}$ cell stimulation also causes immune-related adverse events (irAEs), such as dermatitis, colitis, hepatitis and hypophysitis. Ipilimumab is currently available in Belgium as a second line of treatment for patients with advanced melanoma, and is used at a dose of $3 \mathrm{mg} / \mathrm{kg}$ of body weight, although higher doses were previously used (up to $10 \mathrm{mg} / \mathrm{kg}$ ). We performed a retrospective analysis to identify melanoma patients treated with ipilimumab at the Ghent University Hospital between 2010 and 2013. Data on symptoms, stage and timing of ipilimumab, response and adverse events were collected with a special attention to endocrine disturbances, going from a limited involvement of one endocrine axis to development of a hypophysitis. We identified a total of 39 patients with stage III $($ No. $=7)$ or stage IV (No. = 32) melanoma, who received a dose of $3($ No. $=31)$ or 10 $($ No. $=8) \mathrm{mg} / \mathrm{kg}$. Six patients developed a severe form of irAEs, including one case of colitis $(2 \%)$, one case of sarcoidosis $(2 \%)$ and 4 cases $(10 \%)$ of hypophysitis. Hypophysitis developed between the second and fourth cycle of ipilimumab administration and was independent of the dose used. We describe four cases of involvement of the pituitary gland during treatment with ipilimumab. When managed with vigilant monitoring and high-dose
\end{abstract}

J. Marlier $(\bowtie) \cdot$ V. Cocquyt $\cdot$ L. Brochez $\cdot$ S. Van Belle

V. Kruse

Department of Medical Oncology, University Hospital Ghent, De Pintelaan 185, 9000 Ghent, Belgium

e-mail: Joke.Marlier@ugent.be corticosteroids, the acute symptoms resolve, but lifelong hormone substitution therapy can be necessary. Involvement of the pituitary axes is a severe side effect of treatment with ipilimumab with an urgent need for the correct medical intervention.

Keywords Ipilimumab - Immunotherapy · Melanoma · Hypophysitis · Autoimmune adverse events

\section{Introduction}

Melanoma, currently representing $10 \%$ of all skin cancers, is an aggressive disease with increasing incidence and a one-year survival from 30 to $60 \%$ in advanced stages. Frequently, young people are affected. The estimated agestandardized rates of new melanoma cases for 2012 were 11.4 per 100,000 for males and 11.0 per 100,000 for females [1]. The male/female ratio of melanoma varies among different countries and among age groups. A male predominance has been recorded in countries with a high melanoma incidence, such as Australia and the United States. The majority of Western and Northern European countries report higher incidence rates in females versus males, whereas in most Central, Eastern and Southern European countries melanoma predominates in men [1]. For the age groups $<44$ years, females show higher incidence rates, with the peak difference in the age group 20-24 years. Males exhibit higher incidence rates after the age of 44 years [2]. Patients diagnosed at an early stage can usually be treated with surgical excision with curative intent, and only a minority of these patients will develop metastatic disease [3, 4]. The lifetime risk of developing melanoma is estimated to be 1 in 50 individuals [5]. 
For decades, patients with advanced melanoma were treated with dacarbazine (DTIC) or high-dose interleukin-2 (IL-2), but remission rates were low and toxicity high. Due to development of alternative treatment approaches, such as immunotherapy (anti-CTLA4 and anti- programmed death1/anti- PD-Ligand) and targeted therapy (Rapid accelerating fibrosarcoma type B oncogene (BRAF) inhibition, extracellular Signal-regulated Kinase Kinase (MEK) inhibition, neuroblastoma RAS viral oncogene homolog (NRAS)inhibition [4, 6]), treatment of patients with advanced melanoma has improved significantly. For the first time in years, an overall survival benefit was demonstrated.

This paper will focus on hypophysitis secondary to ipilimumab, an adverse event that has been reported in clinical trials at incidences ranging from 0 to $17 \%$. The clinical presentation can vary from a disturbance of one axis to development of an adenohypophysitis. Involvement of the pituitary axes can be potentially life-threatening with an urgent need for a correct medical intervention. Therefore, it is important to monitor this clinical problem and start treatment whenever necessary despite the infrequent presentation.

Ipilimumab is a monoclonal antibody against cytotoxic T-lymphocyte antigen4 (CTLA-4). The CTLA-4 receptor, present on $\mathrm{T}$ lymphocytes, works as a negative regulator of $\mathrm{T}$ cell activation, causing a physiological interruption of the activated immune system. Ipilimumab blocks CTLA-4, causing activation of cytotoxic lymphocytes, which results in an immune-mediated anti-tumour response [7-9].

Hodi et al. [10] presented data on efficacy in 2010. In a large clinical trial $(n=676)$, the median overall survival was 10.0 months for patients receiving the combination of ipilimumab and gp100 peptide vaccine compared with 6.4 months among those receiving gp100 alone (hazard ratio for death, 0.68; $P<0.001$ ). The overall survival for patients receiving ipilimumab alone was 10.1 months (hazard ratio for death compared to the gp100 vaccine alone was $0.66 ; P=0.003)$. However, there were more grade 3 and 4 immune-related adverse events observed in patients treated with ipilimumab (10 to $15 \%$ ) as compared with gp100 alone (3\%).

Due to immunostimulation, autoimmunity is a known treatment-related problem, resulting in immune-related adverse events (irAEs) in a significant number of patients $[7,8]$. The most common autoimmune adverse events are dermatitis with rashes, colitis, hepatitis and hypophysitis. Even development of sarcoidosis has been described. Pancreatitis, iridocyclitis, lymphadenopathy, nephritis and neuropathies have also been described. Sometimes, the adverse events can be potentially life-threatening with an urgent need for medical intervention. An example of a lifethreatening adverse event is involvement of the pituitary gland $[9,11]$.
Ipilimumab was approved for the treatment of melanoma by the Food and Drug Administration (FDA) in March 2011 and by the European Medicines Agency in July 2011 for use in advanced (unresectable or metastatic) malignant melanoma [7, 11]. The recommended dose and schedule is $3 \mathrm{mg} / \mathrm{kg}$ by intravenous infusion given every 3 weeks for four doses.

\section{Materials and methods}

We performed a retrospective analysis of the Ghent University Hospital medical records to identify melanoma patients treated with ipilimumab between 2010 and 2013. Of the total 2616 patients seen at our department in this time period, 215 were seen for melanoma, and of them 39 received ipilimumab at a dose of $3(\mathrm{No} .=31)$ or $10 \mathrm{mg} / \mathrm{kg}$ $($ No. $=8)$.

Data on symptoms, stage of disease, dose and timing of ipilimumab, response and adverse events were collected.

\section{Results}

Of the 39 patients treated with ipilimumab, 7 patients had stage III disease, 32 stage IV. Six patients developed a severe adverse event that led to discontinuation of the treatment. Among these 6 patients, 4 patients presented with involvement of the pituitary axis, going from involvement of one or more pituitary axes. Furthermore, 1 of the 6 patients presented with a sarcoidosis and 1 patient with colitis. Regarding involvement of the pituitary axes, we report an onset of symptoms between the second and the fourth cycle of treatment, for doses of $3 \mathrm{mg} / \mathrm{kg}(n=2)$ and $10 \mathrm{mg} / \mathrm{kg}(n=2)$ as well. Here, we describe four cases of hypophysitis. (Symptoms are described following the Common Terminology Criteria for Adverse Events (CTCAE). An overview of clinical picture, hormonal values, initial therapy and follow-up is reported in Tables 1, 2.

Hypophysitis with failure of the thyroid gland, the adrenal and gonadal axis

In January 2010, a 56-year-old patient was diagnosed with a non-ulcerating malignant melanoma on the right hypochondrium with a Breslow thickness of $2 \mathrm{~mm}$. A broad resection with sentinel procedure was performed. Stage was pT1apN1cM0.

In May 2010, the patient was included in the adjuvant study with ipilimumab (dose $10 \mathrm{mg} / \mathrm{kg}$ ). Two months after the initial dose of ipilimumab, she complained of severe headache, asthenia and diminished libido. Hormonal investigations showed a failure of the thyroid, adrenal and 
Table 1 Clinical characteristics

\begin{tabular}{|c|c|c|c|c|}
\hline & Case 1 & Case 2 & Case 3 & Case 4 \\
\hline Gender & Female & Male & Male & Male \\
\hline Age & 56 & 31 & 81 & 78 \\
\hline TNM stage & pT1aN1cM0 & pT3bN2M0 & pT2aN0M0 & Stage IV \\
\hline Dose & $10 \mathrm{mg} / \mathrm{kg}$ & $10 \mathrm{mg} / \mathrm{kg}$ & $3 \mathrm{mg} / \mathrm{kg}$ & $3 \mathrm{mg} / \mathrm{kg}$ \\
\hline Indication Ipilimumab & Adjuvant & Adjuvant & Metastatic disease & Metastatic disease \\
\hline \# Cycle onset symptoms & 2 & 4 & 3 & 2 \\
\hline Diagnose & $\begin{array}{l}\text { Hypophysitis with failure of } \\
\text { thyroid, adrenal and gonadal } \\
\text { axis }\end{array}$ & $\begin{array}{l}\text { Hypophysitis with } \\
\text { failure of } \\
\text { adrenal axis }\end{array}$ & $\begin{array}{l}\text { Hypophysitis with failure } \\
\text { of thyroid and adrenal } \\
\text { axis }\end{array}$ & $\begin{array}{l}\text { Hypophysitis with } \\
\text { failure of thyroid and } \\
\text { adrenal axis }\end{array}$ \\
\hline Treatment & $\begin{array}{l}\text { L-Thyroxine }+ \text { Hydrocortisone } \\
+ \text { Dehydroepiandrosterone }\end{array}$ & Hydrocortisone & $\begin{array}{l}\text { L-Thyroxine }+ \\
\text { Hydrocortisone }\end{array}$ & $\begin{array}{l}\text { L-Thyroxine }+ \\
\text { Hydrocortisone }\end{array}$ \\
\hline $\begin{array}{l}\text { Follow-up ( } \Delta \text { time onset } \\
\text { symptoms-last } \\
\text { consultation) }\end{array}$ & $24 \mathrm{~m}$ (Disease free) & 17 m (PD) & $3 \mathrm{~m}$ (PD) & $6 \mathrm{~m}(\mathrm{PD})$ \\
\hline
\end{tabular}

Key clinical characteristics of four patients with advanced melanoma who received ipilimumab and developed secondary hypophysitis

$P D$ progressive disease

Table 2 Overview symptoms, hormonal values, initial therapy and follow-up

\begin{tabular}{|c|c|c|c|c|c|c|c|c|}
\hline Patient & \multicolumn{2}{|l|}{1} & \multicolumn{2}{|l|}{2} & \multicolumn{2}{|l|}{3} & \multicolumn{2}{|l|}{4} \\
\hline Start Ipilimumab & \multicolumn{2}{|c|}{$18 / 5 / 2010$} & \multicolumn{2}{|c|}{$30 / 11 / 2010$} & \multicolumn{2}{|c|}{ 7/10/2010 } & \multicolumn{2}{|c|}{ 7/12/2012 } \\
\hline Onset endocrine $\mathrm{AE}$ & \multicolumn{2}{|c|}{$2 / 7 / 2010$} & \multicolumn{2}{|c|}{$04 / 2011$} & \multicolumn{2}{|l|}{$12 / 2010$} & \multicolumn{2}{|c|}{$14 / 1 / 2013$} \\
\hline $\begin{array}{l}\text { Symptoms (Grade III-IV } \\
\text { CTCAE) }\end{array}$ & \multicolumn{2}{|c|}{$\begin{array}{l}\text { Headache asthenia } \\
\text { diminished libido }\end{array}$} & \multicolumn{2}{|c|}{$\begin{array}{l}\text { Fatigue muscle weakness } \\
\text { pain Diarrhoea } \\
\text { Hypotension }\end{array}$} & \multicolumn{2}{|c|}{ Lethargy adynamia } & \multicolumn{2}{|c|}{$\begin{array}{l}\text { Headache photophobia } \\
\text { phonophobia }\end{array}$} \\
\hline Hormonal values & Onset & FU (27/7/2011) & Onset & FU (01/2011) & Onset & FU $(02 / 11)$ & Onset & FU (07/2013) \\
\hline $\mathrm{ACTH} / \mu \mathrm{g} / \mathrm{dL}(<46)$ & $<5$ & $<1$ & $<5$ & $<5$ & NA & NA & 14 & NA \\
\hline DHEA/ $\mu \mathrm{g} / \mathrm{dL} *$ & 18.76 & 3.4 & NA & 51.33 & NA & 13.61 & NA & NA \\
\hline Cortisol $* * / \mu \mathrm{g} / \mathrm{dL}$ & 0.4 & $<0.2$ & 1.1 & 0.1 & 4.6 & 47.6 & 0.9 & NA \\
\hline $\mathrm{TSH} / \mu \mathrm{U} / \mathrm{mL}(0.27-4.2)$ & 0.025 & 3.67 & 1.4 & 3.5 & $<0.002$ & 0.038 & 0.19 & NA \\
\hline $\mathrm{GH} / \mathrm{ng} / \mathrm{mL}(<8)$ & 0.68 & NA & 5 & $<0.05$ & NA & NA & NA & NA \\
\hline $\mathrm{FSH}^{* * *} / \mathrm{mU} / \mathrm{mL}$ & 4.9 & 25.5 & 2.9 & 2.9 & 0.63 & 1.1 & 6.2 & NA \\
\hline 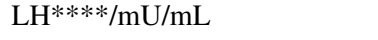 & 0.59 & 11.4 & 2.4 & 2 & 0.64 & 1.4 & 1.1 & NA \\
\hline Supportive medication (Start) & \multicolumn{2}{|c|}{$\begin{array}{l}\text { Levothyroxine } 75 \\
\text { hydrocortisone } 15-10- \\
15 \mathrm{mg}\end{array}$} & \multicolumn{2}{|c|}{ Hydrocortisone $15-10-5$} & \multicolumn{2}{|c|}{$\begin{array}{l}\text { Levothyroxine } 75 \\
\text { hydrocortisone } 15-10-5\end{array}$} & \multicolumn{2}{|c|}{$\begin{array}{l}\text { Levothyroxine } 75 \\
\text { hydrocortisone } \\
15-10-5\end{array}$} \\
\hline $\begin{array}{l}\text { Supportive medication } \\
\text { (Follow-up) }\end{array}$ & \multicolumn{2}{|c|}{$\begin{array}{l}\text { DHEA-s } 2.5 \\
\text { hydrocortisone } 15-10- \\
2,5\end{array}$} & \multicolumn{2}{|c|}{ Hydrocortisone $15-10-5$} & \multicolumn{2}{|c|}{ Levothyroxine 100} & \multicolumn{2}{|c|}{$\begin{array}{l}\text { Levothyroxine } 75 \\
\text { methylprednisolone } \\
32\end{array}$} \\
\hline Co-medication & \multicolumn{2}{|c|}{$\begin{array}{l}\text { Paracetamol } \\
\text { paracetamol }+ \text { coffeine }\end{array}$} & \multicolumn{2}{|l|}{ None } & \multicolumn{2}{|c|}{$\begin{array}{l}\text { Allopurinol } \\
\text { hydroxyethylrutosiden } \\
\text { fesoterodine ranitidine }\end{array}$} & \multicolumn{2}{|c|}{$\begin{array}{l}\text { Lanoxine simvastatine } \\
\text { acetylsalicylic acid }\end{array}$} \\
\hline Imaging (MR) & \multicolumn{2}{|c|}{$\begin{array}{l}\text { Enlarged pituitary gland } \\
1.4 \times 1 \times 1 \mathrm{~cm}\end{array}$} & \multicolumn{2}{|c|}{$\begin{array}{l}\text { Enlargement of the stalk } \\
\text { and the posterior part } \\
\text { of the pituitary gland }\end{array}$} & \multicolumn{2}{|l|}{ Normal } & \multicolumn{2}{|c|}{$\begin{array}{l}\text { Normal pituitary gland } \\
\text { leptomeningeal } \\
\text { metastases }\end{array}$} \\
\hline
\end{tabular}

$N A$ not available, Data in grey-meaning a value below the reference interval

a Female: $35.4-256 \mu \mathrm{g} / \mathrm{dL}$, Male: $160-449 \mu \mathrm{g} / \mathrm{dL}$; ${ }^{\mathrm{b}}$ Morning: 5.15-27.6 $\mu \mathrm{g} / \mathrm{dL}$, Afternoon: $1.85-15.4 \mu \mathrm{g} / \mathrm{dL}$; ${ }^{\mathrm{c}}$ Female: Follicular $3-13 \mathrm{mU} /$ $\mathrm{mL}$, ovulatory $5-22 \mathrm{mU} / \mathrm{mL}$, luteal $2-8 \mathrm{mU} / \mathrm{mL}$, after menopause $>26 \mathrm{mU} / \mathrm{mL}$. Male: $1-12 \mathrm{mU} / \mathrm{mL} ;{ }^{\mathrm{d}}$ Female: Follicular $2-13 \mathrm{mU} / \mathrm{mL}$, periovulatory $14-96 \mathrm{mU} / \mathrm{mL}$, luteal $1-11 \mathrm{mU} / \mathrm{mL}$, postmenopausal $8-59$. Male: $1-9 \mathrm{mU} / \mathrm{mL}$ 
gonadal axes. The diagnosis of hypophysitis was confirmed with a magnetic resonance of the pituitary gland. There was no evidence of brain metastases. Ipilimumab was discontinued and hormonal substitution was started (L-thyroxine, hydrocortisone and dehydroepiandrosterone).

Currently, the patient is still on hormonal replacement therapy. She still needs periodically laboratory follow-up and radiographic imaging because of a persistent secondary adrenal insufficiency.

Regarding her melanoma, the patient is still disease-free and in follow-up.

\section{Hypophysitis with failure of the ACTH axis}

This patient, a 31-year-old man, was diagnosed with a superficial spreading melanoma on the left flank in September 2010. The pathologic examination showed following results: Breslow thickness $2.3 \mathrm{~mm}$, Clark level 4 and a focal ulceration of $0.3 \mathrm{~mm}$. There was no invasion of the vessels and no positive cutting edges. A sentinel procedure was performed and showed metastatic invasion of 3 nodes. A broad excision was performed. The final stage was pT3bN2M0 (stage IIIB).

Ipilimumab was started in an adjuvant study setting $(10 \mathrm{mg} / \mathrm{kg})$. Two months after administration of the fourth cycle (20 weeks after initiation of ipilimumab), the patient developed fatigue, muscle weakness and pain at both calves. Hormonal investigations showed a normal thyroid function, normal gonadal function and adequate IGF1 level but undetectable ACTH, cortisol and low DHEAS levels, typical for an isolated failure of the ACTH axis. Ipilimumab was discontinued and substitution with hydrocortisone was started. After just 1 month on treatment, the patient developed a gastroenteritis with hypotension and hypokalaemia possibly suggesting an adrenal crisis, even if hyperkalaemia should be more typically expected. The natremia was normal. After 6 months, there was still no recovery of the ACTH production and currently the patient still needs substitution therapy.

Seventeen months after finishing therapy with ipilimumab, the patient presented a locoregional relapse, treated with surgical resection. Several new relapses have been diagnosed meanwhile for which he is treated surgically.

Hypophysitis with hypothyroidism and secondary adrenal insufficiency

In 2005 an 81-year-old man developed a lentigo maligna of the scalp completely resected. During the next 2 years, the patient relapsed four times with in-transit metastases secondary to the melanoma of the scalp. In February 2008, he developed metastatic disease and systemic treatment was started. Chemotherapy with dacarbazine was prescribed (200 mg/days, d1-d5, q4w). After 3 cycles of chemotherapy, the patient presented with progressive disease. Second line treatment with a cisplatinum-chemotherapy-doublet was started. After six cycles, the patient had stable disease, and treatment was stopped.

Two years later (May 2010), the patient developed a metastatic lymph node at the right site of his neck. Staging with PET-CT confirmed metastatic disease (a micronodule at the right upper lung lobe and one at the left under lobe). After resection of the pathologic node, third line therapy with ipilimumab $(3 \mathrm{mg} / \mathrm{kg})$ was started. After only three cycles, the patient complained about progressive lethargy and adynamia. There was no fever, diarrhoea, palpitations or alopecia. He also had mild headache without photo- or phonophobia. MRI could not argument an image of hypophysitis. On the other hand, CT thorax and abdomen showed diffuse lung and liver metastases and voluminous bronchial lymph nodes bilateral. Hormonal investigation demonstrated hypothyroidism and secondary adrenal insufficiency. Ipilimumab was discontinued and substitution therapy with hydrocortisone and L-thyroxine was started. Treatment resulted in a rapid improvement of the clinical symptoms. Unfortunately, the patient developed a very fast progression of his disease and best supportive care was started. He finally died 3 months after the start of ipilimumab. Substitution therapy was needed during the whole period of survival.

Hypophysitis with secondary adrenal deficiency and thyroid dysfunction

A 78-year-old male patient was diagnosed in April 2012 with a metastatic melanoma, with lung and liver metastasis.

First line chemotherapy, DTIC $(200 \mathrm{mg} / \mathrm{m} 2$, d1-D5, $\mathrm{q} 3 \mathrm{w}$ ) was started. After 3 cycles, the patient presented with progressive disease. Second line therapy with ipilimumab (3 $\mathrm{mg} / \mathrm{kg}$ ) was initiated in December 2012. After the second infusion, the patient complained about unilateral parietal palpitating headache as well as mild photo- and phonophobia. The complaints improved by administration of corticoids. Biochemical evaluation revealed a hypophysitis with secondary adrenal deficiency and thyroid dysfunction in January 2013. Further therapy with ipilimumab was discontinued and treatment with hydrocortisone was started. To date, 7 months after the diagnosis of hypophysitis, the patient still needs substitution therapy with methylprednisolone and levothyroxine.

Two weeks after discontinuation of ipilimumab, brain metastases were diagnosed. The patient underwent radiotherapy. We chose not to start any other systemic treatment. The patient is followed with best supportive care. 


\section{Discussion}

The side effects caused by ipilimumab can be severe. We report a series of 4 cases of hypophysitis secondary to the administration of ipilimumab in a cohort of 39 patients (10\%) with advanced melanoma.

Hypophysitis secondary to ipilimumab administration, first reported in 2003 [13], is now well described, but the mechanism of pituitary injury remains unknown. It is still unclear whether the effects result from $\mathrm{T}$ cells specifically acting against antigens shared by tumour and normal cells or from the concomitant activation of multiple $\mathrm{T}$ cell populations with separate anti-host and anti-tumour activity [11-13].

In our series, there is no relation with the dose administered, even though some reports suggest a dose-dependent effect not only on efficacy of the drug but also on toxicity, with more side effects occurring at higher doses [14]. Some phase II data suggest that patients experiencing an irAE have a higher chance of an anti-tumour response to ipilimumab and higher irAEs incidences have been associated with longer survival. However, disease control and survival benefits have also been seen in patients without irAEs. Recently, data have been published on the association between the occurrence of irAEs and ipilimumab efficacy based on the Expanded Access Program in Italy [15]. The results of the exploratory analysis suggest that the efficacy of ipilimumab is not related to the occurrence of irAEs. Disease survival and benefits with ipilimumab were similar among patients with or without irAEs [15]. Furthermore, recently, data have been published on the use of ipilimumab in the elderly. Despite risk of serious adverse events, ipilimumab is considered a feasible treatment option [14].

Mostly, the immune-related adverse events can be handled with the administration of corticosteroids. Highdose corticosteroids for treatment of the irAEs do not appear to impair the anti-tumour response [17, 18]. It is generally accepted that the hypophysitis is not reversible. Long-term, even lifelong hormone therapy will frequently be required [16]. The incidence of hypophysitis due to ipilimumab has been reported to range from 0 to $17 \%$ in clinical trials for melanoma and for renal cell carcinoma. Anatomic evaluation of the pituitary gland with MRI in conjunction with serial biochemical evaluations may be helpful in monitoring therapy-induced hypophysitis and preventing life-threatening side effects [19, 20]. It may also be helpful in the differential diagnosis of melanoma to consider both brain metastasis and hypophysitis as autoimmune reaction. In our series, the posterior pituitary function remained normal in all the cases in accordance with the literature, suggesting a possible predilection of ipilimumab for corticotrophic and probably thyrotrophic cells [21].
Table 3 Management of hypophysitis toxicity in patients receiving ipilimumab

\begin{tabular}{|c|c|c|}
\hline $\begin{array}{l}\text { Toxicity } \\
\text { Grade }\end{array}$ & $\begin{array}{l}\text { Ipilimumab } \\
\text { discontinuation }\end{array}$ & Management \\
\hline 1 & No & $\begin{array}{l}\text { Asymptomatic or mild symptoms; } \\
\text { clinical or diagnostic observations } \\
\text { only; intervention not indicated }\end{array}$ \\
\hline 2 & Yes & $\begin{array}{l}\text { If symptoms do not resolve within } \\
1 \text { week of ipilimumab } \\
\text { discontinuation, start glucocorticoids } \\
\text { (such as, prednisone } 0.5 \mathrm{mg} / \mathrm{kg} / \mathrm{day} \text { ) }\end{array}$ \\
\hline 3 & Yes & $\begin{array}{l}\text { Start high-dose glucocorticoids (such } \\
\text { as, prednisone } 1-2 \mathrm{mg} / \mathrm{kg} / \mathrm{day} \text { ). When } \\
\text { symptoms diminish to grade } 1 \text { or less, } \\
\text { taper gradually the steroids over the } \\
\text { course of } 1-2 \text { months }\end{array}$ \\
\hline 4 & Yes & Same as for grade 3 \\
\hline
\end{tabular}

Legend Management of hypophysitis toxicity related to ipilimumab

For moderate grade 2 immune-mediated toxicities, treatment with ipilimumab should be discontinued and should not be resumed until toxicity is grade 1 or less. Corticosteroids (prednisone $0.5 \mathrm{mg} / \mathrm{kg} / \mathrm{day}$ or equivalent) should be started if symptoms do not resolve within a week. For patients with severe or life-threatening grade 3/4 toxicities, treatment with ipilimumab should be permanently discontinued and high doses of corticosteroids (prednisone 1 to $2 \mathrm{mg} / \mathrm{kg} /$ day or equivalent) are indicated. When symptoms diminish to grade 1 or less, steroids can be gradually tapered and stopped over at least one month [9]. Several case-reports have shown that even after significant immune-mediated toxicities, re-induction of treatment may be possible. This permits ongoing therapy with long-term survival. However, restarting ipilimumab has to be discussed individually with the patient to evaluate riskbenefit versus other treatment options (Table 3).

Ipilimumab associated irAEs are consistent with its immune-based mechanism of action. Most frequently the irAEs occur during the induction phase of treatment (0-12 weeks) and when managed with treatment guidelines comprising vigilant monitoring and high-dose corticosteroids, the median time to resolution is approximately 6 weeks for grade 2 irAEs and 8 weeks for grade 3 and 4 irAEs [22].

To conclude, in this series, we report 4 cases of a severe endocrine adverse event during treatment with ipilimumab. Of all patients treated with ipilimumab at our institution, $10 \%$ presented with a hypophysitis with involvement of one or more pituitary axes. We document the cases with detailed clinical information regarding symptoms and relevant biochemical values. For all patients, except for patient 4 , we report the biochemical values by diagnosis and at follow-up. Due to a quick deterioration of the 
clinical situation, we did not evaluate the hormonal values after initiation of therapy for patient 4 . Administration of corticosteroid was continued only based on symptoms and clinical presentation. The problem of hypophysitis can be associated with severe headache besides the panhypopituitarism as described. This was not the case for any of our patients. If a severe and persistent headache is present, high-dose corticosteroids are recommended. However, due to the adverse events related to the use of high-dose corticosteroids, such as induction of an extreme Cushing status as well as hypertension, osteoporosis, aseptic necrosis and diabetes mellitus type 2 on the long term, this is not standard for every patient with a hypophysitis. For all patients, we report low values of ACTH and cortisol at diagnosis indicating a secondary adrenal insufficiency. Due to the palliative setting of all patients, this was not confirmed with an ACTH stimulation test. For patient 1, 3 and 4, we report low TSH as well. The absence of a few data can be considered as a limitation of our series, only due to the retrospective character of the data reporting.

Nevertheless, endocrine side effects associated with the immunotherapy will need more clinical awareness in the near-coming future. Several clinical trials are ongoing and even more trials will be started to further evaluate the role of immunotherapy in metastatic melanoma and other cancer types; to improve survival rates and maybe even cure for this highly aggressive disease. Still, new treatments may cause new side effects. It will be an inevitable challenge to recognize and treat the adverse events on an early stage without compromising the possible beneficial effects of the new treatments.

Conflict of interest The authors have nothing to disclose and indicate no potential conflicts of interest.

\section{References}

1. Nikolaou $\mathrm{V}$ et al. Emerging trends in the epidemiology of melanoma. Br. J. Dermatol. 170(1), 11-19 (2014)

2. F. Liu et al., A unique gender difference in early onset melanoma implies that in addition to ultraviolet light exposure other causative factors are important. Pigment Cell Melanoma Res. 26(1), 128-135 (2013)

3. G. Berthod et al., Pulmonary sarcoid-like granulomatosis induced by ipilimumab. J. Clin. Oncol. 30(17), e156-e159 (2012)

4. S. Andrews et al., Characteristics and management of immunerelated adverse effects associated with ipilimumab, a new immunotherapy for metastatic melanoma. Cancer Manag. Res. 4, 299-307 (2012)
5. Fong ZV et al. Comparison of melanoma guidelines in the United States, Canada, Europe, Australia and New Zealand: A critical appraisal and comprehensive review. Br. J. Dermatol. 170(1), 20-30 (2014)

6. S. Wilgenhof et al., Sarcoidosis in a patient with metastatic melanoma sequentially treated with anti-CTLA-4 monoclonal antibody and selective BRAF inhibitor. Anticancer Res. 32(4), 1355-1359 (2012)

7. J.M. Jeter et al., Ipilimumab pharmacotherapy in patients with metastatic melanoma. Clin. Med. Insights Oncol. 6, 275-286 (2012)

8. A. Juszczak et al., Ipilimumab: a novel immunomodulating therapy causing autoimmune hypophysitis: a case report and review. Eur. J. Endocrinol. 167(1), 1-5 (2012)

9. J.S. Weber et al., Management of immune-related adverse events and kinetics of response with ipilimumab. J. Clin. Oncol. 30(21), 2691-2697 (2012)

10. F.S. Hodi et al., Improved survival with ipilimumab in patients with metastatic melanoma. NEJM 363(8), 711-723 (2010)

11. F. Torino et al., Hypophysitis induced by monoclonal antibodies to cytotoxic $\mathrm{T}$ lymphocyte antigen 4: challenges from a new cause of a rare disease. Oncologist 17(4), 525-535 (2012)

12. S.M. Corsello et al., Endocrine side effects induced by immune checkpoint inhibitors. J. Clin. Endocrinol. Metab. 98(4), 1361-1375 (2013)

13. G.Q. Phan et al., Cancer regression and autoimmunity induced by cytotoxic T lymphocyte-associated antigen 4 blockade in patients with metastatic melanoma. Proc. Natl. Acad. Sci. U S A 100(14), 8372-8377 (2003)

14. J.D. Wolchok et al., Ipilimumab monotherapy in patients with pretreated advanced melanoma: a randomised, double-blind, multicentre, phase 2, dose-ranging study. Lancet Oncol. 11(2), 155-164 (2010)

15. D. Giacomo et al., Correlation between efficacy and toxicity in pts with pretreated advanced melanoma treated within the Italian cohort of the ipilimumab expanded access programme (EAP). J. Clin. Oncol. 31, 9065 (2013)

16. Chandra et al., Evaluating the safety of anti-CTLA-4 therapy in the elderly with unresectable melanoma. J. Clin. Oncol. 31, 9063 (2013)

17. P. Boasberg et al., Ipilimumab: unleashing the power of the immune system through CTLA-4 blockade. Semin. Oncol. 37(5), 440-449 (2010)

18. P. Tomasini et al., Ipilimumab: its potential in non-small cell lung cancer. Ther. Adv. Med. Oncol. 4(2), 43-50 (2012)

19. Z.R. Barnard et al., Hyponatremia associated with ipilimumabinduced hypophysitis. Med. Oncol. 29(1), 374-377 (2012)

20. K.J. Carpenter et al., Ipilimumab-induced hypophysitis: MR imaging findings. AJNR Am. J. Neuroradiol. 30(9), 1751-1753 (2009)

21. L. Min et al., Association of ipilimumab therapy for advanced melanoma with secondary adrenal insufficiency: a case series. Endocr. Pract. 18(3), 351-355 (2012)

22. J.S. Weber et al., Patterns of onset and resolution of immunerelated adverse events of special interest with ipilimumab: detailed safety analysis from a phase 3 trial in patients with advanced melanoma. Cancer 119(9), 1675-1682 (2013) 